\title{
A Rapid Increase in CAMP in Response to 20-Hydroxyecdysone in the Anterior Silk Glands of the Silkworm, Bombyx mori
}

\author{
Mohamed Elmogy ${ }^{\dagger}$, Jun Terashima ${ }^{\ddagger}$, Masatoshi Iga, \\ Masafumi Iwami and Sho Sakurai* \\ Division of Life Sciences, Graduate School of Natural Science and Technology, \\ Kanazawa University, Kakumamachi, Kanazawa 920-1192, Japan
}

\begin{abstract}
In the anterior silk glands (ASGs) of the silkworm, Bombyx mori, intracellular cAMP increases transiently to a very high level shortly after the hemolymph ecdysteroid peak in the prepupal period. In cultured ASGs obtained on the day of gut-purge, cAMP levels were increased by 20-hydroxyecdysone (20E), and this increase was enhanced by an inhibitor of phosphodiesterase, but was not affected by $\alpha$-amanitin, indicating the $20 \mathrm{E}$ action may not be mediated via gene expression. The increase in CAMP occurred within $\mathbf{3 0}$ seconds of exposure to a physiological concentration of $20 \mathrm{E}$ $(1 \mu \mathrm{M})$, and also by ponasterone $\mathrm{A}$. Our findings indicate a nongenomic action of ecdysteroids in insects, which may be an additional mechanism by which this steroid hormone induces acute responses in tissues and cells.
\end{abstract}

Key words: ecdysone, cAMP, silk gland, programmed cell death, Bombyx mori

\section{INTRODUCTION}

Steroids elicit various physiological responses by modulating gene expression through interaction with their nuclear receptors that serve as ligand-dependent transcription factors (Beato and Klug, 2000; Henrich, 2005). 20Hydroxyecdysone (20E), the biologically active form of ecdysone, is essential for inducing molecular and cellular events underlying molting and metamorphosis in insects and crustaceans (Gilbert et al., 1996; Henrich et al., 1999). $20 \mathrm{E}$ exerts its effects via direct binding to a heterodimeric nuclear receptor, EcR/USP, which modifies the transcriptional activity of target genes (Riddiford et al., 2000).

In addition to the genomic action of steroids, increasing evidence of rapid, non-genomic steroid effects has accumulated for virtually all groups of steroids in vertebrates and plants (Lösel and Wehling, 2003). Some responses to mammalian steroid hormones such as estrogen and aldosterone are known to follow nongenomic pathways, beginning with the elevation of intracellular cAMP (Falkenstein et al., 2000; Lösel and Wehling, 2003). A nongenomic action of 20E has also been postulated to occur in insect cells because of its rapid effects. $20 \mathrm{E}$ reduces the amplitude of excitatory potentials at neuromuscular junctions within minutes in the crayfish (Cooper and Ruffner, 1998) and Drosophila (Ruffner et al., 1999).

These acute responses to $20 \mathrm{E}$ fail to fit the classical

\footnotetext{
* Corresponding author. Phone: +81-76-264-6250;

Fax : +81-76-264-6255;

E-mail: ssakurai@kenroku.kanazawa-u.ac.jp

† Present address: Department of Entomology, Faculty of Science, Cairo University, Giza, Egypt

‡ Present address: Graduate School of Pharmaceutical Science, Tohoku University, Aramaki, Aoba-ku, Sendai 980-8578 Japan doi:10.2108/zsj.23.715
}

genomic model, and appear instead to rely on mechanisms involving membrane receptors and second messengers. $20 \mathrm{E}$ increases cAMP levels in the pupal wing epidermis of Hyalophora gloveri (Applebaum and Gilbert, 1972), although the increase is not remarkable (2.5-fold over control levels). In Mamestra brassicae, injection of 20E results in an increase in CAMP in the larval fat bodies $3 \mathrm{~h}$ after injection (Sass et al., 1983). These earlier studies indicated an invoIvement of CAMP in the action of $20 \mathrm{E}$, although the evidence was not conclusive.

The anterior silk gland (ASG) of the silkworm degenerates shortly after pupation (Chinzei, 1975; Terashima et al., 2000). After spinning cocoons at the end of the larval stage, the ASGs begin to undergo programmed cell death (PCD) in response to a high hemolymph ecdysteroid concentration, which induces pupal metamorphosis (Terashima et al., 2000). Since $20 \mathrm{E}$ acts through binding to a heterodimeric ecdysone receptor, EcR/USP (Yao et al., 1992), which serves as a transcription factor, 20E-induced PCD has been considered to begin with de novo gene expression (Huet et al., 1993). However, this was called into question by results obtained with $\alpha$-amanitin, a potent inhibitor of RNA polymerase II. $\alpha$-Amanitin prevents PCD induction by 20E when added to a culture of ASGs with $20 \mathrm{E}$ from the beginning of the culture, whereas its addition $8 \mathrm{~h}$ after the exposure to $20 \mathrm{E}$ does not, indicating that the gene transcription needed for the PCD is accomplished by $8 \mathrm{~h}$. Nevertheless, withdrawal of $20 \mathrm{E}$ from the culture medium between 8 and $42 \mathrm{~h}$ of the culture interferes with the progression of the PCD sequence (Terashima et al., 2000). These previous results suggested a non-genomic action of $20 \mathrm{E}$ until $42 \mathrm{~h}$, following its genomic action in the first $8 \mathrm{~h}$.

Here we determined the changes in intracellular cAMP levels in ASGs that were exposed to $20 \mathrm{E}$ in vitro, as well as in intact ASGs during the prepupal period. Our study shows 
that CAMP levels exhibit rapid changes both in vivo and in vitro.

\section{MATERIALS AND METHODS}

\section{Animals}

Larvae of the silkworm, Bombyx mori, were reared on an artificial diet at $25^{\circ} \mathrm{C}$ under a photoperiod cycle of $12 \mathrm{~h}$-light/12 h-dark, as described previously (Terashima et al., 2000). Day 0 was designated as the day consisting of a scotophase during which larvae underwent gut purge, and the following photophase; ASGs were dissected during the day 0 photophase, unless otherwise stated.

\section{Hormones and chemicals}

$20 \mathrm{E}$ (Sigma, St. Louis, MO) and ponasterone A (PonA, 25deoxy-20-hydroxyecdysone; Sigma) were dissolved in ethanol (2 $\mathrm{mM}$ ) and stored at $-20^{\circ} \mathrm{C}$ until use. $\alpha$-Amanitin (Sigma) was dissolved in water $(1 \mathrm{mg} / \mathrm{ml})$ and diluted to $10 \mu \mathrm{g} / \mathrm{ml}$ with Grace's medium. The phosphodiesterase inhibitor 1-methyl-3-isobutylxanthine (IBMX, Sigma) was dissolved in dimethylsulfoxide (DMSO). When added to culture media, the inhibitor concentration in DMSO was adjusted so that the final DMSO concentration was less than $5 \%$.

\section{Cultures}

ASGs were rinsed with Grace's medium and cultured separately in $0.3 \mathrm{ml}$ medium at $25^{\circ} \mathrm{C}$ (Terashima et al., 2000). For invitro experiments, one of a pair of ASGs was used as a control gland and the contralateral gland as a test gland.

\section{Measurement of intracellular cAMP}

ASGs were kept at $-80^{\circ} \mathrm{C}$ until cAMP extraction. Frozen ASGs were homogenized in cold $6 \%(\mathrm{~W} / \mathrm{V})$ trichloroacetic acid and centrifuged at $2,000 \times \mathrm{g}$ for $15 \mathrm{~min}$ at $4^{\circ} \mathrm{C}$. The resulting supernatant was washed four times with 5 vols of water-saturated diethyl ether, and the upper ether layer was discarded after each wash. The aqueous extracts and pellets were lyophilized separately and stored at $-20^{\circ} \mathrm{C}$ until cAMP quantification. Amounts of CAMP in extracts were determined with a cAMP Enzyme Immunoassay Kit (Amersham Pharmacia, Piscataway, NJ) according to the manufacturer's instructions and were expressed in $\mathrm{pmol} / \mathrm{mg}$ protein on the basis of the amount of protein in pellets. Four ASGs were used for one measurement.

\section{RESULTS}

\section{Changes in intracellular cAMP levels during the prepu- pal period}

Intracellular cAMP levels were determined from the day of gut purge (day 0) until pupation (Fig. 1A). Shortly after gut purge, cAMP increased transiently to $1.16 \mathrm{pmol} / \mathrm{mg}$ protein, and then decreased to a low level $24 \mathrm{~h}$ thereafter. After remaining at this level for two days, the concentration abruptly increased to a high of $4.08 \mathrm{pmol} / \mathrm{mg}$ protein at the beginning of day 3 photophase, and decreased to a low level $6 \mathrm{~h}$ thereafter. The peak on day 3 appeared approximately $12 \mathrm{~h}$ after the peak titer of ecdysteroid in the hemolymph.

\section{Changes in cAMP levels during culture with 20E}

To examine whether the increase in CAMP was brought about by $20 \mathrm{E}$ in vitro, day 0 ASGs were cultured with or without 20E (1 $\mu \mathrm{M})$ (Fig. 1B). In the absence of $20 \mathrm{E}$, basal cAMP levels remained low, ranging from $0.88-1.34 \mathrm{pmol} /$ mg protein. In the contralateral ASGs that were exposed to continuous 20E, the cAMP level began to increase at $18 \mathrm{~h}$
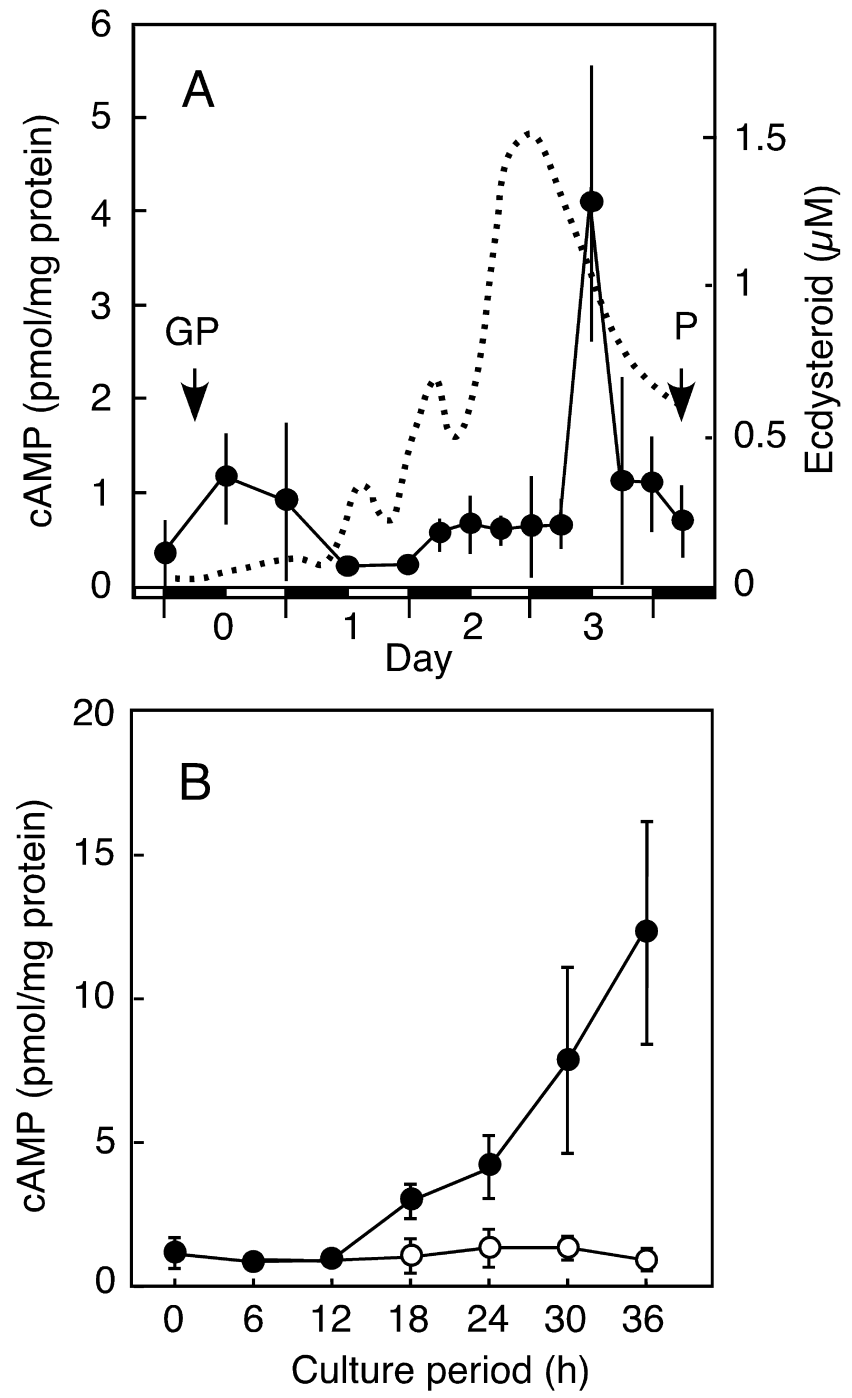

Fig. 1. Changes in intracellular CAMP levels in ASGs in vivo and in vitro. (A) Changes in cAMP during the prepupal period. GP, gut purge; $P$, pupation. The dotted line indicates the changes in ecdysteroids in hemolymph (Terashima et al., 2000). Open and filled bars indicate day and night, respectively. (B) In vitro increase in cAMP by 20E. Day 0 ASGs were cultured with continuous 20E (1 $\mu \mathrm{M})$ (closed circles) or in medium alone (open circles), and cAMP levels were determined every $6 \mathrm{~h}$. Each datum point is a mean $\pm \operatorname{SD}(n=3)$.

of culture, and at $24 \mathrm{~h}$ attained a value similar to the highest recorded in vivo, after which it continuously increased to $12.2 \mathrm{pmol} / \mathrm{mg}$ protein at $36 \mathrm{~h}$.

\section{Effects of 20E on cAMP levels}

The above results showed that it takes more than $12 \mathrm{~h}$ for cAMP to increase in response to $20 \mathrm{E}$. Our previous results (Terashima et al., 2000) indicated that a nongenomic action of $20 \mathrm{E}$ could be involved after $12-18 \mathrm{~h}$ of the culture with $20 \mathrm{E}$. This suggested that pre-culture of the ASGs with $20 \mathrm{E}$ might be necessary to examine the $20 \mathrm{E}$ effects on CAMP. In addition, we inserted a culture period in a hormone-free medium so as to clarify the 20E effects (Fig. 2). Day 0 ASGs were cultured with $20 \mathrm{E}(1 \mu \mathrm{M})$ for 6,12 , 18, or $24 \mathrm{~h}$ (pre-culture), followed by culture in a hormone-free 

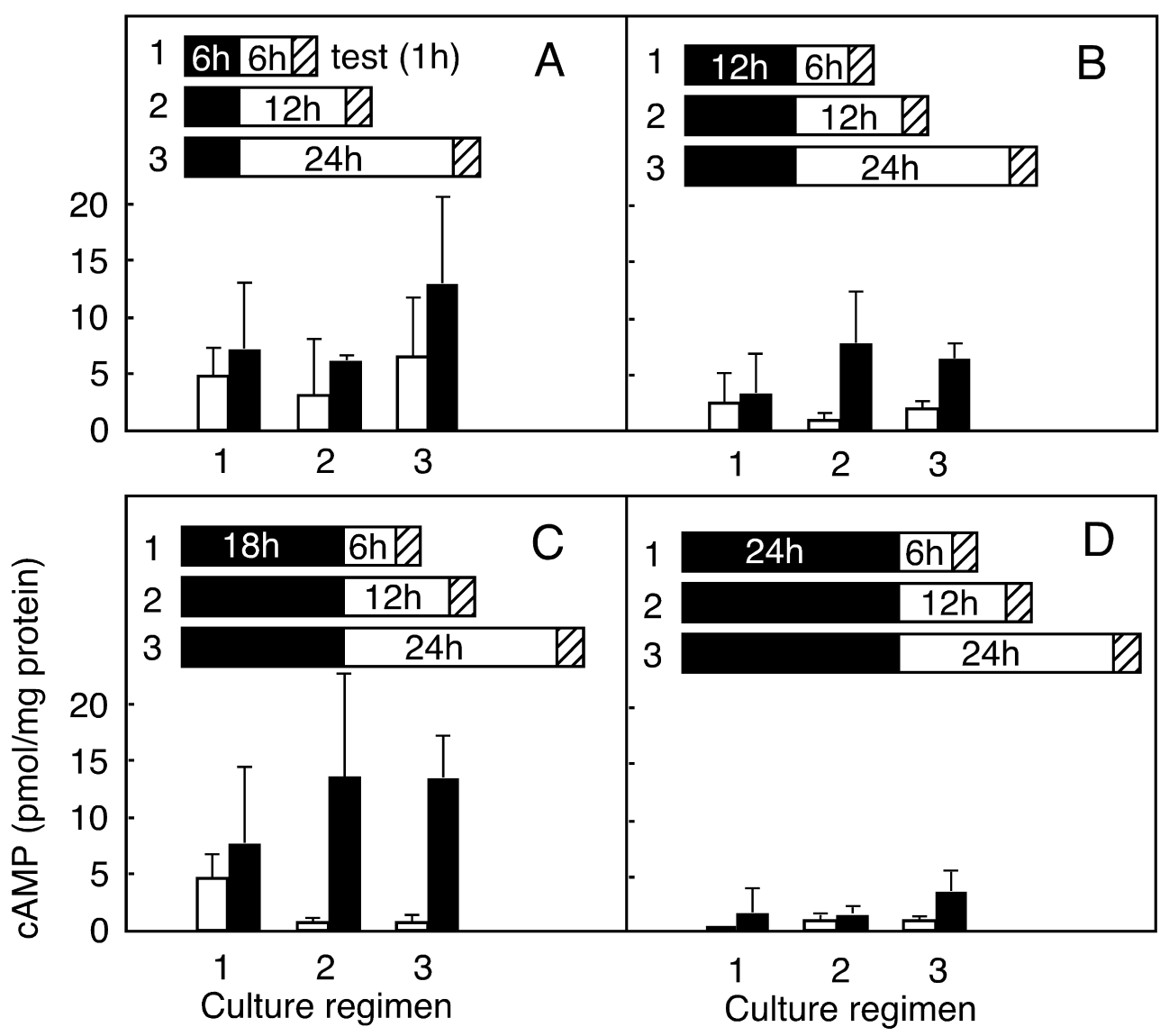

Fig. 2. Effects of insertion of a $20 \mathrm{E}$-free period on the increase in cAMP levels. (A-D) Optimum conditions for examining the 20E effects on the increase in CAMP levels were determined by changing the periods of pre-culture with $20 \mathrm{E}$ and the second culture without $20 \mathrm{E}$. Day 0 glands were cultured with $1 \mu \mathrm{M} 20 \mathrm{E}$ for (A) $6 \mathrm{~h},(\mathrm{~B}) 12 \mathrm{~h},(\mathrm{C}) 18 \mathrm{~h}$, or (D) $24 \mathrm{~h}$, and were further cultured in the absence of $20 \mathrm{E}$ for 6,12 or $24 \mathrm{~h}$ (indicated in each panel). The ASGs were then again exposed to $20 \mathrm{E}(1 \mu \mathrm{M})$ for $1 \mathrm{~h}$ (closed bars) or incubated in medium alone for $1 \mathrm{~h}$ (open bars), and cAMP was measured. Each datum point is a mean $\pm S D(n=3)$.

medium for 6,12 , or $24 \mathrm{~h}$ (second culture), and then the glands were incubated with or without $20 \mathrm{E}$ for $1 \mathrm{~h}$. Under the culture regimen with a $6 \mathrm{~h}$ pre-culture (Fig. 2A), cAMP levels after culture without $20 \mathrm{E}$ were quite high, which obscured the $20 \mathrm{E}$ effects. In the culture regimen with a $12 \mathrm{~h}$ pre-culture, followed by a second culture for 12 or $24 \mathrm{~h}, 20 \mathrm{E}$ significantly increased cAMP levels, but the stimulation was not very prominent (Fig. $2 \mathrm{~B}$ ). In contrast, a culture regimen consisting of an $18 \mathrm{~h}$ pre-culture with $20 \mathrm{E}$ and a second culture for $12 \mathrm{~h}$, cAMP levels increased by 20 -fold (Fig. 2C). Similarly, an 18-fold increase was recorded after the second culture for $24 \mathrm{~h}$. Although the high stimulation was partly due to the low basal levels, the absolute values of cAMP were also the highest among the experimental regimens. Pre-culture for $24 \mathrm{~h}$ was far less effective than that for 18h (Fig. 2D). Accordingly, a pre-culture with $20 \mathrm{E}$ for $18 \mathrm{~h}$, and a second culture in a hormone-free medium for $12 \mathrm{~h}$, was considered to be the most suitable culture regimen.

\section{Effects of $\alpha$-amanitin and IBMX on the cAMP response to 20E}

The effects of $20 \mathrm{E}$ on the increase in cAMP could be nongenomic, similar to mammalian steroid hormones (Falkenstein et al., 2000), although $20 \mathrm{E}$ has been believed to exert its effects via a genomic pathway (Gilbert et al., 1996; Henrich et al, 1999). To address this issue, $\alpha$-amanitin was added to the 1-h incubation with $20 \mathrm{E}$ after the culture regimen that gave the maximal increase in cAMP (Fig. 3A). $\alpha$ Amanitin did not affect the CAMP increase in response to 20E. We next examined the effects of IBMX on the 20E effects by adding IBMX with $20 \mathrm{E}$ after the second culture and incubating the ASGs for 1-3 h (Fig. 3B). IBMX did not elicit any effect in $1 \mathrm{~h}$, but cAMP levels in the ASGs incubated in the presence of IBMX were significantly higher than in the absence of IBMX at 2 and $3 \mathrm{~h}$. These results indicate that $20 \mathrm{E}$ may increase cAMP production.

\section{Time-course and ecdysteroid-concentration responses for cAMP}

The time course of the changes in cAMP showed that CAMP increased within 30 seconds after the 20E challenge, and attained a plateau level at $10 \mathrm{~min}$, after which it did not decline (Fig. 4A). Although cAMP levels appeared to increase until $60 \mathrm{~min}$, there was no significant difference between the levels at 10 and $60 \mathrm{~min}$. Concentration-responses were examined for $20 \mathrm{E}$ and PonA (Fig. 4B). Both ecdysteroids elicited an increase in cAMP levels in a concentration-dependent manner, and the effect of PonA was 

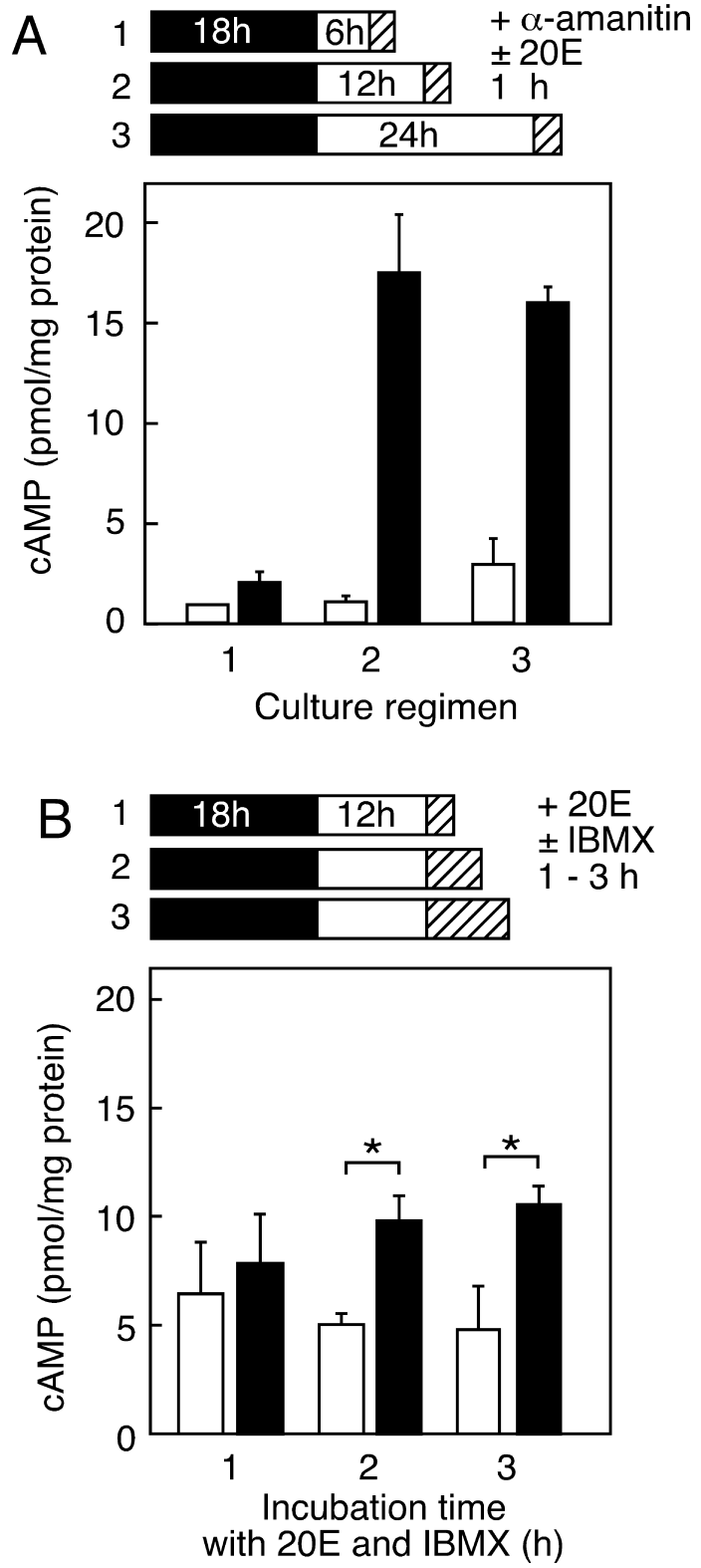

Fig. 3. Effect of $20 E$ on cAMP is nongenomic. (A) Day 0 ASGs were cultured with $20 \mathrm{E}(1 \mu \mathrm{M})$ for $18 \mathrm{~h}$ followed by a second culture in a hormone-free medium for $6 \mathrm{~h}, 12 \mathrm{~h}$, or $24 \mathrm{~h}$. The ASGs were then incubated for $1 \mathrm{~h}$ in the presence of $\alpha$-amanitin alone $(10 \mu \mathrm{g} /$ $\mathrm{ml}$; open bars) or $\alpha$-amanitin and 20E (closed bars). (B) Effects of the phosphodiesterase inhibitor 3-isobutyl-1-methylxanthine (IBMX) on cAMP levels. Day 0 ASGs were cultured with $20 \mathrm{E}(1 \mu \mathrm{M})$ for 18 $\mathrm{h}$, followed by a second culture for $12 \mathrm{~h}$. The ASGs were then incubated in the presence of $20 \mathrm{E}$ alone (open bars) or $20 \mathrm{E}$ and $0.1 \mathrm{mM}$ IBMX (filled bars) for $1 \mathrm{~h}, 2 \mathrm{~h}$, or $3 \mathrm{~h}$. Asterisk indicates a significant difference in cAMP level at $P<0.05$ (ANOVA). Individual culture programs are indicated above the graphs. Each datum point is a mean $\pm \operatorname{SD}(n=3)$.

slightly higher than that of $20 \mathrm{E}$.

\section{DISCUSSION}

A rapid increase in intracellular cAMP levels in response to $20 \mathrm{E}$ and the inability of $\alpha$-amanitin to suppress the increase suggest that $20 \mathrm{E}$ may act through mechanisms
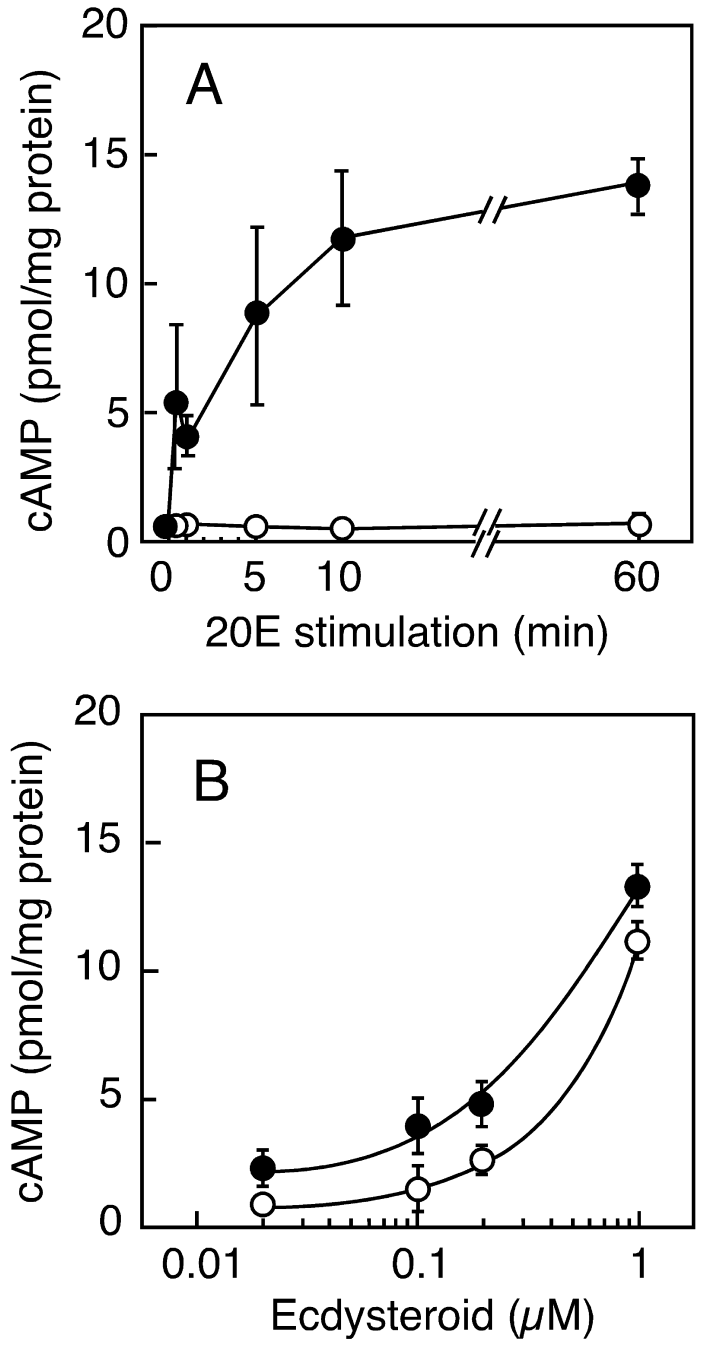

Fig. 4. Quick response of ASGs to 20E. (A) Time course for the increase in cAMP in response to 20E. Day 0 ASGs were cultured with $20 \mathrm{E}(1 \mu \mathrm{M})$ for $18 \mathrm{~h}$, followed by a second culture in a hormonefree medium for $12 \mathrm{~h}$. The glands were then challenged by $1 \mu \mathrm{M}$ $20 \mathrm{E}$ (closed circles) or incubated in medium alone (open circles) for various time-periods. (B) Ecdysteroid concentration dependency. ASGs were cultured with $20 \mathrm{E}(1 \mu \mathrm{M})$ for $18 \mathrm{~h}$ followed by a second culture in a hormone-free medium for $12 \mathrm{~h}$, and then exposed to various concentrations of $20 \mathrm{E}$ (open circles) or PonA (closed circles) for $1 \mathrm{~h}$. Each datum point is a mean $\pm \operatorname{SD}(n=3)$.

that are unrelated to its genomic action. Effects of steroid hormones on intracellular CAMP and adenylate cyclase activity have been described in vertebrate tissues (Falkenstein et al., 2000), but there is only one report based on in vitro experimental results using insect tissues. In the moth Hyalophora glover, 20E enhances adenylate cyclase activity in the pupal wing epidermis within 10 min after exposure in vitro (Applebaum and Gilbert, 1972). 20E thus provokes an increase in CAMP in two different tissues, the wing epidermis and the ASGs, indicating that 20E-cAMP signaling could occur in various tissues in insects.

Several steroid hormones have been shown to exert rapid effects on cells by interacting with specific G-proteincoupled receptors (GPCRs) present on the cell surface (Lösel and Wehling, 2003; Simoncini and Genazzani, 2003; 
Filardo et al., 2002; Zhu et al., 2003; Revankar et al., 2005). In Drosophila, the dopamine/ecdysteroid receptor functions as a cell-surface GPCR, although 20E and PonA suppress the increase in cAMP by dopamine (Srivastava et al., 2005). In mammalian cells, estrogen increases the intracellular cAMP level via a specific GPCR (Filardo et al., 2002). A membrane ecdysteroid receptor could similarly mediate the rapid increase in CAMP levels in ASG cells, although further studies are necessary to determine whether a membrane receptor is involved in the activation of adenylate cyclase.

The correlation between increases in CAMP and the progression of PCD seems to be negative. A sharp increase in cAMP occurred at the time when the ASGs were capable of undergoing $P C D$ without further $20 \mathrm{E}$ stimulation in vivo. Execution of PCD in ASGs begins in response to a high hemolymph ecdysteroid concentration in day-2 photophase, which induces pupation (Terashima et al., 2000). In addition, the increase in cAMP occurred approximately $24 \mathrm{~h}$ or less after the large increase in hemolymph ecdysteroids. In an invitro culture system, CAMP began to increase after $18 \mathrm{~h}$ of culture with 20E. Although the increases in cAMP levels, both in vivo and in vitro, concomitant with the progression of PCD implies an involvement of CAMP in this process, this hypothesis is tenuous, since neither the membrane-permeable cAMP analog dibutyryladenosine 3',5'-cyclic monophosphate (dbcAMP) nor cAMP-dependent protein kinase peptide inhibitor (PKA inhibitor) affected PCD at all (Iga and Sakurai, unpublished data). Consequently, cAMP may not be involved in modulation of the rate of PCD, and its role in this process remains obscure.

\section{ACKNOWLEDGMENTS}

This work was supported by a Grant-in-Aid for Scientific Research from the Japan Society for the Promotion of Science (No. 14360033) to S.S.

\section{REFERENCES}

Applebaum SW, Gilbert LI (1972) Stimulation of adenyl cyclase in pupal wing epidermis by $\beta$-ecdysone. Dev Biol 27: 165-175

Beato M, Klug J (2000) Steroid hormone receptors: an update. Hum Reprod Update 6: 225-236

Chinzei Y (1975) Biochemical evidence of DNA transport from the silk gland to the fat body of the silkworm, Bombyx mori. $\mathrm{J}$ Insect Physiol 21: 163-171

Cooper RL, Ruffner ME (1998) Depression of synaptic efficacy at intermolt in crayfish neuromuscular junctions by 20 -hydroxyecdysone, a molting hormone. J Neurophysiol 79: 1931-1941

Falkenstein E, Tillmann H, Christ M, Feuring M, Wehling M (2000) Multiple actions of steroid hormones - a focus on rapid, nongenomic effects. Pharmacol Rev 52: 513-555
Filardo EJ, Quinn JA, Frackelton AR Jr, Bland KI (2002) Estrogen action via the G protein-coupled receptor, GPR30: stimulation of adenylyl cyclase and cAMP-mediated attenuation of the epidermal growth factor receptor-to-MAPK signaling axis. Mol Endocrinol 16: 70-84

Gilbert LI, Rybczynski R, Tobe S (1996) Endocrine cascade in insect metamorphosis. In "Metamorphosis: Post-embryonic Reprogramming of Gene Expression in Amphibian and Insect Cells" Ed by LI Gilbert, J Tata, P Atkison, Academic Press, San Diego, pp 59-107

Henrich VC (2005) The ecdysteroid receptor. In "Comprehensive Molecular Insect Science Vol 3" Ed by LI Gilbert, K latrou, SS Gill, Academic Press, San Diego, pp 243-285

Henrich VC, Rybczynski R, Gilbert LI (1999) Peptide hormones, steroid hormones, and puffs: mechanisms and models in insect development. Vitam Horm 55: 73-125

Huet F, Ruiz C, Richards G (1993) Puffs and PCR: the in vivo dynamics of early gene expression during ecdysone responses in Drosophila. Development 118: 613-627

Lösel R, Wehling M (2003) Nongenomic actions of steroid hormones. Nat Rev Mol Cell Biol 4: 46-56

Revankar CM, Cimino DF, Sklar LA, Arterburn JB, Prossnitz ER (2005) A transmembrane intracellular estrogen receptor mediates rapid cell signaling. Science 307: 1625-1630

Riddiford LM, Cherbas P, Truman JW (2000) Ecdysone receptors and their biological actions. Vitam Horm 60: 1-73

Ruffner ME, Cromarty SI, Cooper RL (1999) Depression of synaptic efficacy in high- and low-output Drosophila neuromuscular junctions by the molting hormone (20-HE). J Neurophysiol 81: 788-794

Sass M, Csikos G, Komuves L, Kovacs J (1983) Cyclic AMP in the fat body of Mamestra brassicae during the last instar and its possible involvement in the cellular autophagocytosis induced by 20-hydroxyecdysone. Gen Comp Endocrinol 50: 116-123

Simoncini T, Genazzani AR (2003) Nongenomic actions of sex steroid hormones. Eur J Endocrinol 148: 281-292

Srivastava DP, Yu EJ, Kennedy K, Chatwin H, Reale V, Hamon M, Smith T, Evans PD (2005) Rapid, nongenomic responses to ecdysteroids and catecholamines mediated by a novel Drosophila G-protein-coupled receptor. J Neurosci 25: 6145-6155

Terashima J, Yasuhara N, Iwami M, Sakurai S (2000) Programmed cell death triggered by insect steroid hormone, 20-hydroxyecdysone, in the anterior silk gland of the silkworm, Bombyx mori. Dev Genes Evol 210: 545-558

Yao TP, Segraves WA, Oro AE, McKeown M, Evans RM (2005) Drosophila ultraspiracle modulates ecdysone receptor function via heterodimer formation. Cell 71: 63-72

Zhu Y, Rice CD, Pang Y, Pace M, Thomas P (2003) Cloning, expression, and characterization of a membrane progestin receptor and evidence it is an intermediary in meiotic maturation of fish oocytes. Proc Natl Acad Sci USA 100: 2231-2236

(Received March 10, 2006 / Accepted April 20, 2006) 